\title{
Temporalidades articuladas: integração nacional e escrita da história de Minas Gerais, Goiás e Amazônia na Primeira República ${ }^{1}$
}

Fabíula Sevilha*

\begin{abstract}
RESUMO
O artigo analisa a problemática da integração de Minas Gerais, Goiás e Amazônia à nação brasileira no pensamento de Nelson de Senna, Americano do Brasil e Raimundo Moraes, com vistas a entender as narrativas históricas elaboradas por eles na Primeira República (1889-1930). Especificamente, examina como estes autores articularam as temporalidades de um passado a ser (re)construído e um presente a ser superado, a fim de projetar um futuro glorioso para as suas regiões. Para lograr uma integração com efetiva e destacada participação, era fundamental reverter a estagnação econômica e livrar-se dos estigmas de barbárie e insalubridade, motivo pelo qual concentraram muitos de seus escritos em torno dessas problemáticas.
\end{abstract}

Palavras-chave: integração nacional. Primeira República. Historiografia brasileira.

\section{Articulated temporalities: national integration and writing of history of Minas Gerais, Goiás and Amazônia in the First Republic}

\begin{abstract}
The article analyzes the problem of the Minas Gerais, Goiás and Amazônia integration into the Brazilian nation in the thoughts of Nelson de Senna, Americano do Brasil and Raimundo Moraes, to understand the historical narratives elaborated by them in the First Republic period (1889-1930). Specifically, it examines how these authors articulated the temporalities of a past to be reconstructed and a present to be overcome in order to project a glorious future into their regions. For an integration with effective and outstanding participation, it was fundamental to reverse the economic stagnation and to get rid of the barbarism and insalubrity stigmas, so they concentrated many of his writings around these problematic ones.
\end{abstract}

Keywords: National integration. First Republic. Brazilian historiography.

Artigo recebido em 13 jan. 2019.

Aprovado em 22 abr. 2019.

\footnotetext{
* Pesquisadora bolsista PCI-DA do Instituto Nacional da Mata Atlântica - INMA/MCTIC. Doutora em História pela Universidade Federal de Minas Gerais - UFMG; Mestra e Graduada em História pela Universidade Estadual Paulista "Júlio de Mesquita Filho" - Unesp/Assis. E-mail: fsevilhas@yahoo.com.br.
} 


\section{Introdução}

Minas Gerais, Goiás e Amazônia são claros exemplos da voracidade com que o capitalismo colonial adentrou as regiões interioranas do Brasil. Os dois primeiros foram colonizados por sertanistas paulistas à procura de riquezas minerais, e o último por retirantes nordestinos expulsos pelo flagelo das secas. Viveram um curto período de apogeu seguido do declínio da produção. As razões para isso podem ser entendidas como desdobramentos do próprio "sentido da colonização" brasileira, para utilizar o termo cristalizado por Caio Prado Jr. (2000). A valorização momentânea de determinado produto com vistas a atender aos anseios do mercado externo teria colocado essas regiões em constante dependência de uma dinâmica exterior a elas. Muito embora estudos mais recentes já tenham sublinhado que tal dependência não era absoluta, e que havia uma dinâmica interna igualmente relevante, ${ }^{2}$ fato é que a integração ao Estado-nação brasileiro foi, desde o início, superficial, inacabada. Não sem razão, políticos e intelectuais gastaram muito de suas penas dissertando sobre o tema, tornando-o um topos de constantes reivindicações, sobretudo a partir da proclamação de uma República que colocava no horizonte a descentralização e o desenvolvimento regional. Para as regiões elencadas, três nomes merecem destaque.

O primeiro é o de Nelson Coelho de Senna. Nascido em 1876, no Serro, Minas Gerais, bacharelou-se e doutorou-se em Direito, e foi professor de História. Sua entrada na vida política ocorreu em 1907, como deputado estadual. Como parlamentar, foi eleito representante da região de Diamantina e do Vale do Jequitinhonha, no norte mineiro, economicamente estagnada; como intelectual, esteve ligado a uma série de instituições nacionais, regionais e estrangeiras, participando como fundador-benemérito do Instituto Histórico e Geográfico de Minas Gerais, e de seu congênere nacional. Senna dedicou-se, pois, a pesquisar a história das populações e produções mineiras, com o objetivo de promover a arrancada econômica e o desenvolvimento de Minas Gerais e do Brasil. ${ }^{3}$ O segundo autor, Antônio Americano do Brasil, também foi fundador e sócio-correspondente de um Instituto Histórico e Geográfico, o de Goiás. Nascido em 1891, em Bonfim, Goiás, Americano iniciou sua carreira política como integrante do governo daquele que viria a ser seu sogro, João Alves de Castro. Em 1921, foi eleito deputado federal, função que exerceu até 1923, ocupando grande parte da sua carreira política e intelectual com a defesa dos interesses goianos. Para romper o isolamento do estado e alcançar sua modernização e integração à economia nacional, Americano retomou a luta de seu tio-avô, Henrique Silva, pela mudança da capital federal para o Planalto Central. O terceiro e último autor é Raimundo Moraes. Ao contrário dos dois nomes anteriores, esse paraense nascido em Belém, em 1872, concluiu apenas o curso primário e não enveredou pela política, apesar de ter ocupado cargos públicos na Biblioteca Pública e na Imprensa Oficial. Foi como Comandante de Gaiola, espécie de embarcação típica de 
sua região, que Moraes percebeu uma Amazônia ${ }^{4}$ voltada para o estrangeiro e nacionalmente isolada. Como jornalista e escritor, especialmente na obra Na Planície Amazônica, de 1926, fez questão de ressaltar as riquezas da região e denunciar a ausência de comprometimento daqueles que migravam para a Amazônia, exploravam-na e levavam o lucro para fora dali, sem justa contrapartida.

Nosso interesse em Senna, Americano e Moraes reside, principalmente, no fato de terem sido relevantes para o período, mas relegados ao esquecimento pelas gerações posteriores, o que nos permite mapear como a formação da brasilidade foi pensada fora dos centros de debate usualmente trabalhados por muitos especialistas. ${ }^{5}$ Isto posto, o objetivo deste artigo é analisar a problemática da integração no pensamento desses três autores, com vistas a entender a narrativa histórica elaborada para a região de cada um deles. Partimos do pressuposto de que o modus operandi de Senna, Moraes e Americano na escrita da história de Minas, Amazônia e Goiás, respectivamente, além de um projeto político, corresponde ao tensionamento das categorias históricas de "espaço de experiência" e "horizonte de expectativa", conforme propostas por Reinhart Koselleck (2006). Uma vez que os dados da primeira compõem os "diagnósticos" traçados para liberar e orientar os prognósticos da segunda, interessa-nos pensar como tais autores articularam as temporalidades de um passado a ser (re)construído e um presente a ser superado, como forma de projetar o que consideravam um futuro glorioso para as suas regiões. A exemplo do que propõe José Carlos Reis (2017, p. 9), buscaremos nos posicionar entre a "história regional" e a "história geral do Brasil", a fim de explorar a pluralidade das narrativas historiográficas.

\section{Gigantes abandonados}

A distância, as dificuldades de transporte, o clima, tido como inóspito, e a presença indígena e de animais selvagens repeliram durante muito tempo a presença do elemento colonizador no "longínquo" interior do Brasil. Ainda que as primeiras expedições de reconhecimento tenham ocorrido por volta dos séculos XVI e XVII, o incentivo cabal para a sua ocupação veio somente no século XVIII. Referindo-se aos contextos mineiro e goiano, Charles Boxer (1969) aposta num estímulo tríplice, representado pela liberdade pessoal, a ambição do ouro, e o desejo de obter novos ameríndios. Sobre a região amazônica, Victor Leonardi (1999, p. 58; 65) indica três momentos fundamentais: o tráfico de mão-de-obra indígena para os engenhos do Maranhão e de Pernambuco; a procura pelas "drogas do sertão", que atraiu comerciantes de várias nacionalidades; e a corrida pela borracha, esta, sim, responsável por um boom no desenvolvimento econômico da região. 
A incursão do branco europeu pelo interior do território luso-brasileiro foi, pois, lenta e teve como pólo atrativo a promessa de ganho fácil. Sertanistas e aventureiros migraram para Minas Gerais e Goiás à procura de ouro e pedras preciosas, e para os seringais amazônicos em busca da hevea brasiliensis. O desejo de cobiça tornava-se maior do que os obstáculos impostos pela natureza e por populações nativas desconhecidas e tidas por selvagens, em luta pela própria sobrevivência. Ocorre que à facilidade de lucro correspondia a rapidez da perda e do despovoamento das regiões por parte do elemento colonizador.

O apogeu aurífero foi, aproximadamente, de 1750 a 1770. A partir de 1780, a produção começa a declinar num crescente. Quase um século depois foi a vez da Amazônia viver situação semelhante. O auge da "febre da borracha" ocorreu entre 1879 e 1912. A mineração declinou tão logo o ouro de superfície esgotou, e os seringais desmantelaram frente à competição britânica nas colônias asiáticas. O que Leonardi (1999, p. 164) descreve para a Amazônia serve para as regiões mineradoras. Segundo ele, a febre da borracha trouxe uma euforia financeira geradora de hábitos e consumos, sedenta da importação em grandes quantidades de produtos supérfluos e luxuosos. Como que num ciclo vicioso, toda a riqueza se esvaía mediante a crença da não-finitude.

$\mathrm{Na}$ interpretação de muitos historiadores,${ }^{6}$ o apogeu foi seguido de decadência, com a ruralização e estagnação dessas sociedades. A historiografia recente tem feito o trabalho de desmistificar interpretações como esta, ainda presas à ideia dos ciclos econômicos. A nosso ver, a ideia de "acomodação evolutiva", de que nos fala Douglas Cole Libby (1988, p. 22), é mais profícua e instrumental para entendermos o contexto econômico das regiões. Se os braços mineiros e goianos se voltaram para a pecuária, e os amazônicos para o extrativismo, isso não significa um retrocesso, mas sim uma diversificação da economia. Por outro lado, em âmbito nacional, os olhos governamentais continuaram vidrados na promessa de ganho fácil, o que, no período em que nossos autores escrevem, estava representado pela cafeicultura.

Nelson de Senna, Americano do Brasil e Raimundo Moraes entendiam que suas regiões eram preteridas, colocadas em segundo plano. $\mathrm{O}$ tom das falas e escritos, como mostraremos na sequência, é de reivindicação de um lugar na política e na história da nação. Ao fim e ao cabo, acreditamos que esses autores não fugiam ao movimento geral observado por Franzini, Gontijo $e$ Oliveira (2018) na historiografia brasileira a partir de 1914, segundo o qual considerava-se urgente voltar ao passado, pois nele estavam não só os vestígios da nacionalidade, como a chave para um futuro modelar que refletisse as singularidades brasileiras. A dinâmica era a de articular temporalidades, isto é, de estabelecer uma continuidade entre passado e futuro, ao mesmo tempo em que era fundamental demarcar uma ruptura, pois entre esses dois tempos históricos havia um presente a ser superado. Mas não só isso! Indo além, é preciso entender nossos autores como reivindicadores de uma história menos centralizadora e excludente. Todos eles se sentiam 
"gigantes" abandonados à própria sorte, e buscavam maneiras de pender favoravelmente a balança para suas respectivas regiões. Mesmo em Moraes, cuja atitude de exaltação da terra amazonense vem misturada a uma quase subordinação ao poder de São Paulo, o descontentamento é gritante. Tanto assim que José Carlos Reis (2017, p. 13) o localiza no interior de um grupo - no qual acrescentaríamos Americano e, em menor grau, Senna - denominado como dos "utópicos": autores profundamente insatisfeitos com os rumos e interpretações vigentes sobre a "história geral do Brasil", desejosos de que as suas interpretações sobre o país encarnem novos protagonistas e expressem novas vozes - nos casos de que estamos tratando, as da Amazônia, de Goiás e de Minas Gerais.

\section{Desfazer os estigmas}

O primeiro passo para a almejada integração ao corpo da nação era se tornar atrativo, isto é, cuidar da construção de uma imagem positiva, o que implicava retomar o passado e reelaborar uma narrativa histórica favorável. De certa maneira, Senna, Americano e Moraes procederam a um tipo de operação historiográfica observada entre os intelectuais ligados ao Instituto Histórico e Geográfico Brasileiro - IHGB, e que consistia em dirigir o processo inventivo a partir de, pelo menos, duas disposições epistemológicas centrais: a depuração dos fatos e a correção de visões deturpadas (Cézar, 2004). Desde princípios da colonização, dois grandes estigmas pesavam sobre Goiás, Amazônia e o norte de Minas Gerais: a barbárie e a insalubridade. No início do século XX, a fronteira de povoamento colonizador mal tinha se alargado para além da divisa mineira com o território goiano e pouco tocava o amazonense. A forte presença indígena reforçava a ideia dessas regiões como a linha limítrofe com o mundo dito civilizado. As peculiaridades climáticas do bioma Cerrado, preponderante em Goiás e em parte de Minas Gerais, e do bioma amazônico, como as cheias sazonais de seus rios, eram não raras vezes vistas como vetores de doenças. Era contra essas concepções negativas que Nelson de Senna, Americano do Brasil e Raimundo Moraes deveriam lutar para fazer dessas regiões um chamariz ao Estado e aos capitalistas. As estratégias escolhidas caminharam no sentido da aceitação e da negação.

Os representantes mineiro e goiano apostaram na temática da miscigenação, tônica tão controversa quanto elucidativa para a história da historiografia brasileira de meados do século XIX às primeiras décadas do século XX. Colocado por Karl Friedrich Von Martius (1845) como um elemento positivo na formação social brasileira, em proposta vencedora do concurso realizado pelo IHGB, o "cruzamento das três raças" teve inserção lenta entre os principais historiadores do período. Segundo Ronaldo Vainfas (1999), a proposta foi tão inovadora "que ninguém na verdade a seguiu ao longo do século XIX". Francisco Adolpho de Varnhagen a teria ignorado, persistindo 
com uma "História branca, elitista e imperial", e Capistrano de Abreu, muito embora tenha deslocado o eixo interpretativo do litoral para o interior, apenas a tangenciou, via de regra reiterando estereótipos. Até o limiar dos anos 1930, já com Gilberto Freyre, a historiografia brasileira teria tratado a miscigenação como problema moral ou patológico, de cuja cura dependia o futuro da Nação. Oscilava-se entre o desalento frente à constatação de que a mescla cultural gerou um país diferente da Europa, e a percepção do negro e do indígena como corruptores de um projeto civilizacional. A "solitária exceção", afirma Vainfas, teria sido Manoel Bomfim, o primeiro, desde Martius, a reconhecer na miscigenação um aspecto positivo da formação do povo e da cultura brasileira.

No entanto, o que autores ainda mais relegados ao esquecimento do que o próprio Bomfim podem nos mostrar, é que, nesse tema em específico, a sua voz não ecoava sozinha. Guardadas as proporções cabíveis a cada um, Senna e Americano também se debruçaram sobre a mescla racial e cultural, contribuindo com interpretações acerca de como tais fatores podem ser vistos positivamente na nacionalidade brasileira. Certamente não com o mesmo radicalismo lusofóbico do viés bomfiniano, e ainda que tomando como limite uma lente que partia do regional para o nacional, há nesses autores e em seus escritos das três primeiras décadas do século XX um elogio à miscigenação. Estudos mais recentes dedicados à história intelectual e à história da historiografia brasileira têm, inclusive, evidenciado que esta não era exatamente uma exceção entre a intelectualidade da Primeira República. O tema resvalava em outro igualmente relevante e urgente de ser enfrentado.

Diante da renovação interpretativa que marcou a historiografia na passagem do século XIX para o XX, acessar os estratos mais profundos do passado colonial, isto é, o contexto dos "selvagens", mostrou-se incontornável. Por dois motivos: de um lado, pelo crescente descontentamento com os rumos do republicanismo, e o embate entre Brasil real e Brasil legal, culminando na crescente insatisfação com a forma tomada pela recém-construída nacionalidade (Gomes, 1998; Franzini, Gontijo \& Oliveira, 2018); de outro, pelo novo modelo historiográfico representado por Capistrano de Abreu (1853-1927), e por autores como Eduardo Prado (18601901), Euclides da Cunha (1866-1909) e Teodoro Sampaio (1855-1937), que deslocaram o olhar predominante do litoral para os habitantes do interior do Brasil, valorizando o sertanejo, o caboclo, o mestiço.

De acordo com Franzini, Gontijo \& Oliveira (2018), a "questão indígena" e o "sertão" emergiram não só como objetos enigmáticos indispensáveis para decifrar a história nacional, mas também como importantes categorias de representação dos distintos e simultâneos espaços e tempos da realidade histórica brasileira em um tempo único: o da nação. As temáticas ganharam uma tal força que se desdobraram, inclusive, em disputas intelectuais em torno de onde se 
encontraria o melhor exemplar da mestiçagem e a região mais interiorana e distante do litoral do país, como Eliana Dutra (2005, p. 131) encontrou nas páginas do Almanaque Brasileiro Garnier. Um importante contraponto nesse momento foi a revitalização do discurso identitário de São Paulo como "uma avis rara, uma 'exceção de progresso' em meio aos demais brasileiros (com destaque para os 'nortistas'), vistos como apáticos e dependentes do governo" (Ferreti, 2008, p. 61).

Assim é que Nelson de Senna, certamente o mais empenhado de nossos três autores nesse quesito, realizou estudos sistemáticos sobre o papel do negro e do índio na história de Minas Gerais, e o papel do branco europeu como agente de civilização. Para ele, índios e negros ocupavam um grau de inferioridade racial, por isso a mistura com o branco teria sido essencial. Mas o encontro entre esses povos era visto como um ganho, como o responsável pela singularidade e a força de nossa nacionalidade - ainda em formação:

Cada um desses elementos étnicos (provenientes da mescla entre indígena, europeu e africano), com os quais veio lentamente se fazendo a formação demográfica do Brasil, no correr dos quatro séculos e pouco da nossa existência histórica, representa um expoente da nossa força de adaptação ao solo, cada qual deles resistindo galhardamente às hostilidades do meio físico, desbravandoas e levando-as de vencida (Senna, 2006f [1916], p. 286)

E mais abaixo, continua:

É sempre o mesmo tipo valente, astuto, fiel e bravo que se encontra entre o nosso povo: é o canoeiro do São Francisco; é o tropeiro de Minas; é o jangadeiro do Ceará; é o salineiro de Cabo Frio ou do Mossoró; é o campeiro de gado do Norte de Minas ou dos sertões do Piauí; é o "faiscador" de ouro ou o "garimpeiro" de diamantes da bacia do Jequitinhonha; é o caipira de São Paulo; é o valente capinador "baiano", que vem para os cafezais do sul; é o boiadeiro goiano ou do Triângulo Mineiro; é o jagunço dos sertões nortistas; é o curumim amazônico ou o pescador de Santa Catarina; o barriga verde dos mares da Laguna e da costa do São Francisco do Sul; é o gaúcho das cochilas rio-grandenses; é o campeiro do Mato Grosso. Em todos esses tipos representativos está vivamente caracterizado o nosso povo, a camada da nossa gente simples, trabalhadora $e$ humilde (Senna, 2006f [1916], p. 286)

Ao compor as peças desse quebra-cabeça chamado "povo brasileiro", Nelson de Senna defende uma história plural e reivindica o lugar de Minas Gerais no âmbito da história da nação. É de sua região que vem o canoeiro, o tropeiro, o "faiscador". Estes e os demais tipos sociais acima são congregados na figura do caboclo. As pechas de tristeza e sisudez, que posteriormente se tornaram o mote do modernista Paulo Prado (1997 [1928]), são antes pontos fortes. Tais características foram essenciais para a adaptação ao meio e para a construção do país. Como Martius, o seu conservadorismo não o impedia de acreditar que o cruzamento de raças foi o responsável por criar forças e novas virtualidades (Iglésias, 2000). E para aqueles que duvidassem, 
Senna lançava a pergunta: "Quantas obras notáveis do nosso progresso material teriam fracassado se não fora o auxílio poderoso do braço e da energia muscular, da resistência ao meio físico desse rude caboclo brasileiro?" (Senna, 2006f [1916], p. 287).

Em Americano do Brasil, o ideal de uma raça una, fruto da mistura de branco, negro e índio, envereda pelo viés do organicismo evolucionista (Silva, 1982). Médico de profissão, tal qual Manoel Bomfim, o historiador goiano fazia uma "apologia da mestiçagem concebida em termos de 'cruzamento' positivo de espécies, em detrimento das dimensões étnicas e culturais pertinentes à discussão" (Vainfas, 1999, p. 5). Em seus escritos, a sociedade é entendida como um organismo vivo, sujeita aos mesmos movimentos e leis, inclusive de patologia e cura. Interessante a esse respeito, é a analogia orgânica que faz da formação social brasileira resultante da colonização:

\begin{abstract}
Na consideração macroscópica de nosso organismo social, não poderemos negar que as células brancas, mesmo porque foram mais profusas e melhor talhadas, ocupam o folheto ectodérmico, donde surgirão o cérebro e o revestimento epitelial que um dia, décadas a dentro, hão de homogeneizar as gentes nacionais; as células negras ainda constituem o músculo e o esqueleto da sociedade brasileira, foram $e$ ainda são na maioria dos focos humanos as melhores gentes de trabalho, legando-nos pelo mestiçamento um poderoso cimento qual tecido conjuntivo - valioso contingente de formação de que o futuro declinará o valor centrípeto ou dispersivo: é o folheto mesodérmico de nossa organização; finalmente, as células americanas formam o último folheto da gástrula social: órgãos armazenadores de energia e o dispositivo de absorção (Brasil, 1918, p. 63)
\end{abstract}

O branco europeu como intelecto e o negro como força física era uma ideia corrente à época. Ao entender o indígena como dispositivo de absorção, podemos inferir que o historiador goiano o considera como uma espécie de esponja, capaz de reter os elementos com os quais entra em contato; civilizável, portanto. Ora, isso era fundamental, uma espécie de promissão a uma região onde a presença do índio apresentou-se desde o século XVII como um importante dificultador das tentativas de ocupação e povoamento colonizador, a ponto de no século XIX o governo provincial envidar esforços na construção de aldeamentos para pacificar e absorver a população indígena (Sevilha, 2017). Para Americano, a história goiana e a história nacional resultavam de um processo em que, a partir de uma "medicina especial de regeneração das capacidades étnico-formativas", prevaleceu a superioridade do elemento branco. O produto final foi o mestiço do sertão - o goiano? - que, no seu entendimento, guardava a verdadeira gênese da cultura nacional.

Nelson de Senna e Americano do Brasil se colocam diante do problema de maneira bastante direta, afirmando que o mineiro e o goiano são fruto da mescla racial, moldável por excelência pelos parâmetros da civilização, e que aí está a força e a singularidade de sua gente. 
Raimundo Moraes, por sua vez, tangencia a questão e opta pela negação. As principais características atribuídas ao indígena - tão associado ao habitante amazonense -, que são a vida nômade, a raça amarela e a alimentação frugal, apenas revelam, a seu ver, que ele não pertence à Amazônia; que é "um povo egresso de outros climas, de outros continentes, da Ásia, por exemplo, quiçá das margens do Bramaputra, na encosta do Himalaia, ou, quem sabe?, dos tabuleiros do Tibete, da Mongólia possivelmente, ou, ainda, da Manchúria” (Moraes, 1936 [1926], p. 202).

Ancorando-se na teoria de Bering, segundo a qual o homem chegou à América pelo estreito que liga este continente ao extremo leste do continente asiático, Moraes parece dividido. Por um lado, afirma que o indígena amazônico, ao contrário do nordestino e do habitante da planície ocidental, não se adaptou ao meio, nem mesmo se radicou ao solo. Por outro, atribui o caráter "boêmio" e "indisciplinado" dos índios à facilidade proporcionada pela rica natureza do vale amazônico, que o torna avesso e mesmo incapaz de um trabalho metódico. O paradoxo nos parece apenas aparente e funciona como uma estratégia argumentativa. Não é a abundante natureza que impede que o índio se torne força produtiva, nem mesmo uma força que lhe é intrínseca. Em outras palavras, a indolência não está no meio, e sim na inadaptação às inúmeras possibilidades que a Amazônia oferece, inclusive o contato com a civilização, que lhe é mortal:

\begin{abstract}
Robusto, criado ao sabor das intempéries, virgem dum trapo que lhe cubra o corpo, caça, pesca, planta com todos os sintomas da saúde, sem uma ferida, sem uma doença crônica, sem o menor sinal de estado mórbido. Mal se chega, porém, aos núcleos estranhos, obtendo roupas, utensílios, armas, abrigo, toda a fortaleza do seu perfeito organismo abre-se às doenças. O catarro, o impaludismo, a bexiga, a sífilis, a tuberculose atacam-no logo, devastando gerações inteiras (Moraes, 1936 [1926], p. 211)
\end{abstract}

O indígena não é dali e, ao que lhe parece, nunca será! Uma vez reforçada essa inabilidade de ingresso na civilização, é como se Moraes endossasse a visão do índio como um obstáculo ao progresso. Não se pode dizer que fosse favorável ao extermínio, mas o autor paraense é enfático em afirmar que custava "menos dinheiro e cansaço atrair imigrantes da Europa que manter essa tutela cara e improfícua" (Moraes, 1936 [1926], p. 211) que era a política indigenista. A atenção deveria se voltar para o verdadeiro nativo da Amazônia, o pescador simples, o seringueiro das ilhas. Estes, sim, teriam sido constantemente espoliados, primeiro pela Metrópole, depois pelos turcos.

Seja pela exaltação do caboclo, seja pela negação do indígena, Senna, Americano e Moraes tinham como entrave às suas pretensões a associação entre indolência e clima, e entre este e a insalubridade, que remonta aos primeiros tempos da colonização. Desde que o sucesso da 
empreitada colonial significou a adaptação do europeu ao ambiente das Américas, estabeleceu-se uma forte associação entre clima e inferioridade cultural. Para Montesquieu (1960 [1772]), o clima era o responsável pelos vícios humanos, como a preguiça e a ociosidade. Diante de uma natureza tão próspera, o homem não precisava se esforçar para dominá-la; dela tudo se retirava sem trabalho. Para Buffon (1707-1788), o caráter menos ativo atribuído ao clima dever-se-ia ao fato de que os organismos do Novo Mundo eram primitivos em relação ao velho continente; menores, porque decadentes.

Ainda que Alexander von Humboldt (1767-1835) tenha revolucionado as explicações sobre a natureza americana, contrárias à pretensa juventude do continente (Pratt, 1999, p. 212), as teses monstesquianas e buffonianas ainda não haviam sido completamente abandonadas. $\mathrm{O}$ calor excessivo, característico das zonas tropicais, continuou sendo apontado como razão para a degeneração física e psíquica. É o que demonstra a divisão entre litoral (civilizado) e sertão (bárbaro). As partes mais interiores do Brasil eram entendidas como de natureza bruta e, por conseguinte, de população selvagem. Eram também sinônimo de debilidade e amoralidade. Enquadrá-las no projeto de nação implicava civilizá-las, o que, dentre outras coisas, consistia em "neutralizar os efeitos negativos do clima" e corrigir as tendências naturais desvirtuantes (Corrêa, 2001, p. 11).

O argumento ancorava-se na ideia do meio como um elemento atuante na saúde do corpo e da mente. Nos tratados médicos ditos hipocráticos, as febres já eram atribuídas essencialmente à miasmas presentes no ar, à alimentação ou à água. Com a medicina moderna, partimos para uma visão populacional e polietiológica, segundo a qual "um germe sozinho pode não provocar nenhuma perturbação. Para que a doença se declare é preciso que o sujeito viva num certo meio ecológico e que possua um perfil genético que aceite o agressor" (Sournia \& Ruffie, 1984, p. 215217). Ainda assim, a teoria aerista ou teoria dos miasmas, embasada na concepção de que fluidos corrompidos por detritos orgânicos poderiam contaminar lugares, pessoas e objetos, foi preponderante no Brasil ao longo de todo o século XIX e início do XX.

A fim de tratar sobre esses supostos "efeitos negativos do clima", Moraes menciona tanto o grego Hipócrates (c. 460-370 a.C.) quanto a teoria miasmática para afirmar que o ambiente amazônico, com seus pântanos de águas paradas e mal-cheirosas, e suas árvores aglomeradas a impedir a passagem dos ventos, é, de fato, propício à diluição de miasmas. Conclui, porém, que apesar do clima muitas vezes desfavorável, a maioria das doenças encontradas na região - como a sífilis, a tuberculose e a lepra - é exterior a ela. Trazidas pelos "gaiolas", as enfermidades eram o preço a ser pago pelo progresso. Ao autor paraense, esse "reverso da medalha progressista" apresentava-se como um fator de seleção. Os indígenas não estavam aptos a isso, mas o verdadeiro homem amazônico, sim, desde que as "vozes esclarecidas" que circulavam pela região 
lograssem proteger os mais fracos com "as regras provadas e seguras da higiene e da profilaxia" (Moraes, 1936, p. 190).

O que Moraes evidencia, e que também está de fundo nos outros dois autores, é uma política claramente reformista, em consonância com o movimento intelectual da época. A descoberta do habitante do interior do país revelava a dura realidade de uma população faminta, enferma e analfabeta. Senna, Americano e Moraes esforçaram-se por reverter um jogo claramente desfavorável. Se a população era bárbara e rude, as razões eram externas: o abandono do Estado, a espoliação estrangeira, as doenças da civilização. A imagem do caboclo esquálido, amarelado, de barriga inchada, pé descalço rachado, ignorado pelo Estado e à mercê da própria sorte, padecendo de moléstias típicas da pobreza, foi imortalizada no personagem Jeca Tatu, de Monteiro Lobato (1918). No enredo, Jeca Tatu, um caipira morador do Vale do Paraíba paulista, é rotineiramente acusado de alcoolismo e preguiça, até que um médico se depara com a sua figura miserável e resolve examiná-lo. Diagnosticada a presença da ancilostomose - popularmente conhecida como Amarelão e transmitida por um verme que penetra o corpo humano pela boca, pés, pernas e nádegas -, orienta o Jeca a calçar sapatos. O caipira não apenas se cura, como, livre da fadiga acarretada pela doença, volta a trabalhar.

O "Jeca Tatu não é assim, está assim", dizia o autor. A partir deste, que se tornou o símbolo do homem rural, Monteiro Lobato escancara o problema da saúde pública no interior do Brasil, tema que já vinha sendo trabalhado pelos cientistas de Manguinhos, e era parte do esforço das campanhas sanitárias de nomes como Belisário Pena (1868-1939) e Arthur Neiva (1880-1943), que buscavam a cura e a integração desse elemento ao país. Não nos parece exagero afirmar que Senna, Americano e Moraes procuravam ancorar suas argumentações nesse contexto político $e$ intelectual favorável a debater a questão do abandono e da urgente inserção dos habitantes dos mais distantes rincões brasileiros.

Formado em Medicina, Americano era dos três o mais enfático sobre o papel do Estado na manutenção da saúde pública. Como futuro ideal para a nação, na qual queria se integrar, ele projetava um país constituído de um "brasileiro fisicamente forte, moralmente predisposto, intelectualmente moldável à alfabetização" (Brasil, ACD, 1923, p. 284). Para que esse tipo ideal fosse bem distribuído pelo território nacional, defendia, a concessão de verbas para solução do problema localmente (Silva, 1982). Futuro parecido era almejado por Senna, que sonhava com uma pátria formada de um "povo sadio, forte e jovial", uma "bela raça constituída com os bons elementos eugenéticos que aqui possuímos, vitalizada com o sangue resistente do mestiço e melhorada cada vez mais pela educação moral" (Senna, 2006f [1916], p. 291). O projeto civilizacional voltado à domesticação do caboclo deveria partir da figura do Estado protetor, responsável por lhe ensinar os valores da vida sedentária, os princípios da higiene, o trabalho 
perseverante e produtivo, bem como por corrigir o temperamento dos vícios passageiros. Defensor dos princípios republicanos, explica Vera Alice Cardoso Silva (2006), o historiador mineiro associava democracia com a "qualidade eugênica da população", isto é, defendia a ideia de que somente uma "raça forte" pode gerar homens livres. O principal problema, do seu ponto de vista, era o da puericultura, o de garantir o desenvolvimento de uma infância bem nutrida, de uma prole sadia, pelos cuidados legais em torno da mulher brasileira (Minas Gerais, 1914).

Também para Americano, se havia a esperança de uma raça promissora, as fichas deveriam ser depositadas na infância, protegendo principalmente a criança jogada às "alternativas da miséria, da ausência de higiene e da assistência do Estado, [que] vive ao desamparo, dispondo seu fraco e debilitado organismo à insídia pertinaz de todos os males" (Brasil, ACD, 1923, p. 280281). Já para Moraes, o desafio imposto pelo meio era o maior dos incentivadores. Se o clima era inóspito, era a "energia bem orientada do desbravador" quem deveria "corrigir a natureza". Se o fluxo de pessoas e mercadorias, pedra de toque do progresso, infectava o povo amazônico, isso deveria servir de "melhor estímulo ao esforço saneador do homem" (Moraes, 1936, p. 190). Por suas afirmações, é possível inferir a existência da crença de seleção natural, ou seja, de que a capacidade de adaptação às intempéries do meio é que é capaz de gerar uma "raça forte", pronta para sobreviver à Amazônia, comprometer-se com ela, explorá-la racionalmente e, com isso, inseri-la nos trilhos da modernidade.

O Brasil e sua população mestiça, analfabeta, fora do mundo organizado do trabalho $e$ com baixo envolvimento na vida política da cidade passava ao largo do ideal eurocêntrico de "povo" que as elites almejavam (Carvalho, 2005). Era preciso, portanto, construir o verdadeiro cidadão brasileiro, o que vinha ao encontro de um outro ideal - a "transformação simbólica" da criança em futuro da nação, observável desde o último quartel do século XIX (Hansen, 2007). Ainda que esses temas fossem lugar comum entre os intelectuais do período, convém destacar que adquirem um papel fundamental para Minas Gerais, Goiás e Amazônia por incidirem diretamente sobre os estigmas que nossos autores procuravam combater.

\section{Apontar caminhos}

O esforço de desmantelamento dos estigmas caminhou pari passu ao de exaltação das possibilidades. Senna, Americano e Moraes aproveitaram um contexto político e intelectual que enxergava que o verdadeiro sentimento nacional estava na proposição de medidas de salvação do país (Oliveira, 1990, p. 145). Em termos econômicos, as primeiras décadas do século XX sofriam os impactos da Primeira Guerra Mundial, com a aceleração das exportações e de novas indústrias, e o boom da economia cafeeira (Sevcenko, 1999, p. 07-48). Nesse contexto, nossos 
autores assistiam à entrada de capitais estrangeiros $e$ à concentração destes - e de toda a infraestrutura que eles poderiam proporcionar, como rede ferroviária, industrialização, educação, saúde pública - nas zonas cafeicultoras do Oeste paulista. Se o norte de Minas Gerais, Goiás e Amazônia expusessem as potencialidades lucrativas de seu ambiente natural, talvez conseguissem burlar o favoritismo e atrair investimentos tanto nacionais quanto estrangeiros.

Senna foi o que melhor sintetizou a inquietação que tomava conta de nossos autores:

Como explorar as nossas minas de ferro, cultivar milhares de alqueires de terrenos desaproveitados, fazer nascer novas indústrias nacionais, centuplicar a nossa produção econômica, fazer navegáveis todos os nossos grandes rios, abrir uma rede extensa de estradas de rodagem, etc. contando somente com a indolência, a ignorância e o abatimento físico de milhões de compatriotas que vivem nos remotos sertões sem conhecer o $\mathrm{ABC}$, isolados do mundo, roídos pelo impaludismo e pela malária, irredutíveis na superstição e no atraso? (Senna, 2006c [1917], p. 79)

Nesse sentido, as estratégias se desdobram em três direções. A primeira delas é a de comunicação, tema que já havia sido insistentemente debatido ao longo do Império brasileiro. Para Moraes, já nesse quesito a Amazônia despontava com vantagem. Seu território era banhado pelo rio Amazonas, o segundo maior em extensão do planeta, que nasce no Peru e deságua no Oceano Atlântico. A economia da borracha já havia lhe ensinado a importância deste escoadouro. ${ }^{7}$ A partir dele, a região tinha a perspectiva aberta para o mundo! Bastava produzir racionalmente que suas águas davam conta de distribuir aos mercados consumidores. Nas palavras dele, "Tráfego barato, exercitado ao fio das mais largas avenidas fluviais, esses produtos, no bojo de possantes transatlânticos, irão abastecer os mercados europeus e americanos" (Moraes, 1936 [1926], p. 180).

Sorte semelhante não tinham Minas Gerais e Goiás. Muito embora possuíssem cursos d'água largamente espalhados pelo território, não havia saída direta para o mar e muitos trechos eram encachoeirados, o que dificultava a franca navegação. A tese defendida por Senna é a de que o atraso das regiões mais afastadas e a falta de dinamismo produtivo era fruto do isolamento físico. Dados geográficos e estatísticos ajudam-no a embasar seu argumento de que o estado de Minas Gerais possuía regiões ricas, porém mal exploradas (o Norte, por exemplo). O historiador mineiro tinha consciência de que "uma nova fase de expansão do trabalho e da indústria exigirá também um novo cenário para a atividade material das gerações que nos forem sucedendo", $e$ que, por isso, o Estado deveria investir em expansão dos serviços de correios e telégrafos, da rede ferroviária, e das estradas de rodagem (Senna, 2006d [1910], p. 70). Somente assim o interior poderia distribuir sua produção e contribuir para a industrialização e emancipação econômica do Brasil: 
Vivemos também a proclamar, caluniosamente, Senhor Presidente, que o caboclo brasileiro é indolente. Não o é tal. O que responde o caipira, o rústico, quando é interrogado na intimidade, desfaz tão injusta pecha: "Plantar para quê, se eu não tenho para onde mandar, se o mercado daqui não consome as sobras? E o que todos plantam para o seu sustento!" Devemos levar-lhe não as vias férreas custosas, não a construção de estradas aparatosas, mas, primeiro, a estrada ou caminho vicinal [...] Esta é a salvação de nossa produção agrícola, por exemplo, nos remotos sertões paulistas, mineiros e goianos, de onde as estradas de ferro só devem transportar gêneros de barato custo por fretes mínimos [...] (Senna, 2006g [1923], p. 134).

Americano também acreditava que a penúria de seu estado estivesse vinculada à deficiência de transportes e comunicações, o que fazia com que a economia do sul goiano fosse polarizada por Minas e a do norte do estado pelo Pará e pela Bahia. O grande interlocutor e inspirador para seus projetos de integração foi o seu tio-avô, Henrique Silva. Com ele, fundou a revista A informação Goiana, que já em seu programa inicial (1917, p. 01) apontava como um dos principais objetivos "colocar diante dos olhos dos capitalistas, dos industriais e dos comerciantes as possibilidades econômicas sem conta do Estado mais central e menos conhecido do Brasil”. Não obstante, revitalizou o projeto de José Bonifácio (1763-1838), do qual Silva era um dos maiores entusiastas: a construção da capital no Planalto Central de Goiás. Como justificativa para essa retomada, afirmava: "motivos de ordem financeira e econômica, sobretudo, continuam a indicar aos chefes de Estado que a magna chave do progresso brasileiro está resumida simplesmente na breve fórmula - rumo ao planalto" (Brasil, 1923, p. 136).

Em comum, Senna e Americano nutriam o sonho de que ferrovias, estradas e telégrafos os comunicassem com o futuro, com o progresso, mas também com o passado, a partir do retorno aos "tempos de glória" ofertados pelo apogeu aurífero. A demanda externa por aço, ferro e combustível para subsidiar a indústria bélica e automobilística norte-americana e europeia, durante e após a Primeira Guerra Mundial, serviu de incentivo para que ambos reavivassem o discurso em torno da riqueza mineralógica de seus estados.

Na concepção de Senna não deveria pairar dúvida: o "destino histórico" de Minas Gerais estava nas suas potencialidades minerais. A chave da revitalização econômica mineira - e brasileira - era a siderurgia; aos governantes cabia despertar o estímulo de capitais dos Estados Unidos e da Europa (Senna, 2006a [1907], p. 252). Embora não ignorasse a importância do capital estrangeiro para alavancar a economia, Americano era partidário de uma política nacionalista. Sua projeção de futuro era baseada em uma política de combustível menos dependente (Silva, 1982, p. 93). A autonomia reforçaria os estudos sobre as possibilidades do carvão nacional e, como sua incursão na história da mineração colonial goiana parece ter lhe ensinado, daria perenidade ao empreendimento. $\mathrm{O}$ historiador goiano advertia para a necessidade de não se cometer o mesmo 
erro que a mineração, em que os empresários "caldearam o rico metal para o seu berço de nascimento".

O temor da espoliação estrangeira talvez seja a razão para Moraes, na contramão de Senna e de forma mais incisiva que Americano, optar pelo distanciamento em relação aos "louros" da borracha. A hevea brasiliensis não deveria ser sequer uma opção considerável para ele. A produção alicerçada em torno da ambição pelo "prêmio" imediato, a seu ver, não criava sociedades, mas uma horda de aventureiros itinerantes e descomprometidos com o futuro amazônico. A "aventura fácil da fortuna rápida”, escrevia ele,

[...] não teve jamais população estável, que amasse e concretizasse pelo trabalho o esplendor da nova pátria. Diferente a atualidade. De riqueza fixa, indestrutível, oriunda tão somente das manadas bovinas e numerosas das suas campinas verdoengas, funde, no lance criador do vaqueiro, definida e soberba nacionalidade. Assim sucederá à Amazônia. No dia em que a extração da seringa, do caucho, da madeira se transmude na plantação do arroz, da cana, do milho, do cacau, de acordo com as exigências geográficas, a planície equatorial volver-se-á em fabuloso celeiro do mundo (Moraes, 1936, p. 180).

Calcado na experiência que lhe era temporal e espacialmente tão próxima, parecia a Moraes que havia razões de sobra para rechaçar os frutos do látex. Para ele, o que transformaria a Amazônia de terra inculta em prodigiosa não era o extrativismo, mas sim a indústria agropecuária. De certa forma, o autor paraense seguia a lógica herdada dos fisiocratas, segundo a qual o avanço da civilização estava no desenvolvimento do comércio (Boer, 2007, p. 121-128).

A agropecuária, que emergia como uma nova tábua de salvação para Moraes, em Minas Gerais e Goiás já havia se transformado em uma alternativa em vias de fracassar. De acordo com Americano, as razões para a situação agonizante em que esse setor se encontrava eram: a diminuição da exportação para o estrangeiro, a falta de crédito, e o regime tributário oneroso (Brasil, 1923, p. 57; 59). Senna, por seu turno, advogava em favor de uma mudança de rumo. Da forma como vinha sendo praticada, a pecuária só fazia piorar as condições de trabalho e de vida do caboclo mineiro (Minas Gerais, 1914). Vera Alice Cardoso Silva (2006, p. 47) sintetizou da seguinte forma o ideal de Minas Gerais propalado por Senna: uma sociedade agrária, baseada na pequena propriedade produtora, junto da qual se desenvolveria a agroindústria, "numa divisão de trabalho benéfica para os indivíduos, as famílias e para o Estado". Acreditamos, no entanto, que ele quisesse mais, que a menina dos seus olhos era a exploração mineral, única que no seu entendimento era capaz de atrair investimentos maciços para a região.

Tal afirmação nos coloca imediatamente diante de uma pergunta que pode ser estendida aos outros dois autores. Mas, afinal, de qual capital estamos falando? Qual seria a origem desse capital? Nacional, estrangeiro, regional? Americano, sinalizamos acima, via com reservas o 
investimento estrangeiro, pois temia a repetição da dinâmica colonial e a perpetuação da situação de dependência. A esta postura, comum a outros políticos e intelectuais do período, Senna deu o nome de "falso patriotismo". O autor mineiro dizia-se, naquele momento, favorável a "procurar capitais sem o preconceito de pavilhões ou de línguas, sem o preconceito de raças ou tradições, garantindo por leis sábias a afluência de capitalistas e industriais estrangeiros" (Senna, 2006e [1912], p. 172).

Esse parece também ser o caminho de Moraes. Em nenhum momento ele deixa claro a quem dirige o seu apelo. Fala de maneira bastante genérica em homens sábios, em yankees, mas, na Dedicatória nos dá algumas pistas. Dedica a sua obra à Washington Luís, presidente de São Paulo de 1920 a 1924, e encaminha-o "como humilde oferenda intelectual da radiosa Amazônia ao majestoso estado de São Paulo, cérebro iluminado do Brasil, berço das maiores conquistas nacionais" (Moraes, 1936, p. 08). A julgar por esse enaltecimento, é possível que o foco fosse tanto o projeto paulista de modernização quanto o capital - estrangeiro e nacional - circulante em São Paulo por conta da cafeicultura. Para Reis (2017, p. 275), Moraes foi profundamente influenciado pela geo-história de Euclides da Cunha. Assim, procurava fazer pela Amazônia o que a narrativa euclidiana fez pelo Nordeste, ou seja, enaltecer a sua região não apenas para pedir socorro, mas também para pedir investimentos.

A distância temporal entre a experiência e a expectativa de nossos autores ajuda-nos a elucidar as abordagens acima. Enquanto Moraes viveu, como Comandante de Gaiola, a euforia e a frustração com a febre da borracha, Senna e Americano só formulavam suas opiniões sobre o apogeu minerador a partir de documentos históricos. No entanto, a recuperação do baque do declínio da mineração em Goiás foi mais lenta do que em Minas Gerais, localizado mais próximo dos mercados consumidores e produtores, de modo que para Americano a memória da espoliação colonial talvez estivesse menos desbotada pelo tempo. Esses dois dados tornam mais compreensíveis a sua aversão a qualquer indício de exploração estrangeira e de Moraes ao lucro fácil. Em relação a este, não podemos esquecer que a economia cafeicultora paulista gerava ao seu redor um mercado consumidor dos produtos da pecuária, que possivelmente Moraes quisesse alcançar. Mais realista do que Americano, Senna enxergava a carência estrutural do Brasil e entendia que a abertura ao capital estrangeiro buscava aproveitar o momento favorável à exportação de ferro, aço e carvão, aberto pela Primeira Guerra Mundial. ${ }^{8}$

Com efeito, tornar-se polo atrativo de verbas era essencial para se integrar, pelas vias do mercado, à nação, além de ser condição sine qua non para o progresso, e foi em torno dessa lógica que nossos autores construíram suas propostas. Nesse sentido, o que merece destaque é o modo como Nelson de Senna, Americano do Brasil e Raimundo Moraes partiram de um problema comum, o isolamento, matizando-o com as colorações de seus espaços e tempos. 


\section{Articular temporalidades: considerações finais}

Dissemos no início do artigo que as concepções de "espaço de experiência" e "horizonte de expectativa" seriam norteadoras da análise, e fundamentais para dimensionarmos a intersecção do contexto com o diagnóstico do isolamento e a elaboração de propostas integracionistas. Se as alcunhas de barbárie, indolência e insalubridade repeliam empreitadas ditas civilizacionais em Minas Gerais, Goiás e Amazônia, o momento se mostrava propício à elaboração de novas leituras conceituais. O surgimento das campanhas sanitaristas, a reavaliação de teorias raciais, $\mathrm{O}$ movimento indigenista, o realismo e o modernismo traziam para o centro do debate o interior do país e seus habitantes.

As estratégias mineira, goiana e amazônica para driblar o contexto de isolamento, entendidas no entrecruzamento da experiência com a expectativa, isto é, historicamente, ajudamnos a esclarecer a diversidade de modelos, preceitos e símbolos, muitas vezes antagônicos, existentes no interior de um projeto dito nacional. Evidenciam o caleidoscópio de interpretações possíveis sobre a história dessas regiões, do período e do Brasil. Por outro lado, na medida em que pensam problemas nacionais, Nelson de Senna, Americano do Brasil e Raimundo Moraes deixam de ser autores meramente regionais.

Autores como esses, considerados secundários ou que simplesmente foram relegados ao esquecimento, merecem um olhar mais acurado. Em lugar de uma postura que se contente em taxá-los de meras reproduções dos grandes cânones historiográficos e conceituais, é preciso apreender como estes foram subvertidos, remodelados, adequados aos seus anseios. Isto porque, esses "autores menores" têm muito a revelar dos usos políticos da história, das aplicações efetivas do discurso histórico enquanto prática social (Certeau, 2008). Apenas para ficarmos no tema da miscigenação, seus escritos mostram que, entre a análise lusofóbica levada a termo pela voz "dissonante" e "heterodoxa" (Reis, 2006, p. 186) de Manoel Bomfim, e o diagnóstico sombrio de Paulo Prado, existiu uma miríade de interpretações, menos polarizadas, mas não menos instrumentais para os objetivos a que se destinavam. São escritos que carregam consigo os diversos projetos e visões históricas concorrentes, no geral esmaecidos pelos modelos e narrativas historiográficas vencedoras. Em outras palavras, trazem elementos complexificadores das visões hegemônicas, e nos remetem a uma história plural, composta por diversos "Brasis".

\section{Fontes}

BRASIL. A Informação Goiana. Rio de Janeiro, 1917-1918. 
BRASIL. Anais da Câmara dos Deputados (ACD). Rio de Janeiro, 1923.

BRASIL, Antonio Americano do. Pela Terra Goyana (Discursos Parlamentares - 1922). $2^{\circ}$ volume. Rio de Janeiro: Imprensa Nacional: 1923.

MINAS GERAIS. Discurso proferido por Nelson de Senna na 42a sessão ordinária da Câmara dos Deputados, aos 23 de setembro de 1914. Anais da Câmara dos Deputados (ACD). Quarta Sessão da 6a Legislatura, 1914.

MORAES, Raimundo. Na Planície Amazônica (Brasiliana, 63). São Paulo: Cia Editora Nacional, 1936 [1926].

SENNA, Nelson Coelho de. A função social do Estado e a desapropriação de Minas para fins públicos. In: GUSTIN, Fádua Maria de Souza \& LANNA JÚNIOR, Mário Cléber Martins (orgs.). Memória Política de Minas Gerais - Nelson Coelho de Sena. Belo Horizonte: Fundação João Pinheiro-Centro de Estudos Históricos e Culturais, 2006a [1907], p. 247-260.

SENNA, Nelson Coelho de. A Proteção dos trabalhadores rurais e da pequena propriedade. In: GUSTIN, Fádua Maria de Souza \& LANNA JÚNIOR, Mário Cléber Martins (orgs.). Memória Politica de Minas Gerais - Nelson Coelho de Sena. Belo Horizonte: Fundação João Pinheiro-Centro de Estudos Históricos e Culturais, 2006b, p. 271281.

SENNA, Nelson Coelho de. Minas e sua ação preponderante para a defesa da pátria. In: GUSTIN, Fádua Maria de Souza \& LANNA JÚNIOR, Mário Cléber Martins (orgs.). Memória Politica de Minas Gerais - Nelson Coelho de Sena. Belo Horizonte: Fundação João Pinheiro-Centro de Estudos Históricos e Culturais, 2006c [1917], p. 7880 .

SENNA, Nelson Coelho de. O desenvolvimento de Minas Gerais e sua riqueza literária. In: GUSTIN, Fádua Maria de Souza \& LANNA JÚNIOR, Mário Cléber Martins (orgs.). Memória Politica de Minas Gerais - Nelson Coelho de Sena. Belo Horizonte: Fundação João Pinheiro-Centro de Estudos Históricos e Culturais, 2006d [1910], p. 69-77.

SENNA, Nelson Coelho de. O falso patriotismo e a necessidade de capital estrangeiro para o desenvolvimento. In: GUSTIN, Fádua Maria de Souza \& LANNA JÚNIOR, Mário Cléber Martins (orgs.). Memória Politica de Minas Gerais - Nelson Coelho de Sena. Belo Horizonte: Fundação João Pinheiro-Centro de Estudos Históricos e Culturais, 2006e [1912], p. 167-179.

SENNA, Nelson Coelho de. Pátria e Raça. In: GUSTIN, Fádua Maria de Souza \& LANNA JÚNIOR, Mário Cléber Martins (orgs.). Memória Politica de Minas Gerais - Nelson Coelho de Sena. Belo Horizonte: Fundação João Pinheiro-Centro de Estudos Históricos e Culturais, 2006f [1916], p. 282-292. 
SENNA, Nelson Coelho de. Riquezas naturais, desenvolvimento econômico e expansão industrial do Brasil. In: GUSTIN, Fádua Maria de Souza \& LANNA JÚNIOR, Mário Cléber Martins (orgs.). Memória Política de Minas Gerais - Nelson Coelho de Sena. Belo Horizonte: Fundação João Pinheiro-Centro de Estudos Históricos e Culturais, 2006g [1923], p. 127-140.

\section{Referências}

BOER, Pin Den. Civilização: comparando conceitos e identidades. In: JASMIM, Marcelo Gantus Jasmin; FERES JÚNIOR, João (orgs.). História Dos Conceitos - Diálogos Transatlânticos. Rio de Janeiro: Edições Loyola/IUPERJ, 2007, p. 121-128.

BERTRAN, Paulo. Uma Introdução à História Econômica do Centro-Oeste do Brasil. Brasília: Codeplan, Goiás: UCG, 1988.

BOXER, Charles. A Idade de Ouro do Brasil: dores de crescimento de uma sociedade colonial. São Paulo: Companhia Ed. Nacional, 1969.

BREFE, Ana Cláudia Fonseca. O Museu Paulista: Affonso de Taunay e a memória nacional. São Paulo: Editora Unesp: Museu Paulista, 2005.

BRUNO, Ernani Silva. História do Brasil - Geral e Regional: grande-oeste. Vol. VI. São Paulo: Cultrix, 1967.

CALDEIRA, Ana Paula Sampaio. O Bibliotecário Perfeito: o historiador Ramiz Galvão na Biblioteca Nacional. Tese (Doutorado em História), CPDOC - Fundação Getúlio Vargas, 2015.

CARVALHO, José Murilo de. Os Bestializados: o Rio de Janeiro e a República que não foi. São Paulo: Companhia das Letras, 2005.

CERTEAU, Michel. A Operação Historiográfica. In: A Escrita da História. São Paulo: Forense Universitária, 2008, p. 65-119.

CÉZAR, Temístocles. Lição sobre a escrita da História: historiografia e nação no Brasil do século XIX. Diálogos, DHI/UEM, vol. 8, n. 1, 2004, p. 11-29.

CORREAA, Lucelinda Schramm. O Caráter Civilizatório das Práticas Higienistas no Século XIX. Revista Geográfica de América Centrai. Número Especial EGAL, Costa Rica, II Semestre 2011, p. 01-12.

COSTA, Francisco de Assis. A Brief Economic History of the Amazon: 1720-1970. 1. ed. New Castle Upon Tyne: Cambridge Scholars Publishing, 2019. 
DUTRA, Eliana de Freitas. Rebeldes Literários da República: história e identidade nacional no Almanaque Brasileiro Garnier (1903-1914). Belo Horizonte: Editora UFMG, 2005.

FERRETTI, Danilo J. Zioni. O uso político do passado bandeirante: o debate entre Oliveira Vianna e Alfredo Ellis Jr. (1920-1926). Estudos Históricos (Rio de Janeiro), vol. 21, 2008, p. 59-78.

FRANZINI, Fabio; GONTIJO, Rebeca; OLIVEIRA, Maria da Glória de. Ordering time, nationalizing the past: temporality, historiography and Brazil's formation. Historein, vol. 17, 2018, p. 01-37.

GOMES, Angela de Castro. A Política Brasileira em Busca da Modernidade: na fronteira entre o público e o privado. In: NOVAES, Fernando; SCHWARCZ, Lilia M. (orgs.). História da Vida privada no Brasiı. São Paulo: Cia das Letras, 1998, vol. 4, p. 489-558.

GOMES, Angela de Castro. A República, a História e o IHGB. Belo Horizonte: Argvmentvm, 2009.

GRAÇA FILHO, Afonso de Alencastro. A princesa do oeste e o mito da decadência de Minas Gerais: São João del Rei (1831-1888). São Paulo: Annablume, São João del Rei: UFSJ, Funtir, 2002.

HANSEN, Patrícia Santos. Brasil, um país novo: literatura cívico-pedagógica e a construção de um ideal de infância brasileira na Primeira República. Tese (Doutorado em História), Universidade de São Paulo, 2007.

HEMMING, John. Arvores de rios - A história da Amazônia. São Paulo: Senac, 2011.

IGLÉSIAS, Francisco. Historiadores do Brasil: capítulos de historiografia brasileira. Rio de Janeiro: Nova Fronteira; Belo Horizonte: UFMG, 2000.

KOSELLECK, Reinhart. Futuro passado. Contribuições à semântica dos tempos históricos. Rio de Janeiro: Contraponto; Ed. PUC-Rio, 2006.

LENHARO, Alcir. As Tropas da Moderação: o abastecimento da corte na formação da política do Brasil, 18081842. São Paulo: Símbolo, 1979.

LEONARDI, Victor. Os Historiadores e os Rios: natureza e ruína na Amazônia brasileira. Brasília: UnB/Paralelo $15,1999$.

LIBBY, Douglas Cole. Transformação e Trabalho em uma Economia Escravista: Minas Gerais no Século XIX. São Paulo: Brasiliense, 1988.

LOBATO, Monteiro. Urupês. São Paulo: Seção de Obras do Estado de S. Paulo, 1918. 
LUCA, Tania Regina de. A Revista do Brasil: um diagnóstico para a (N)ação. São Paulo: Fundação Editora da UNESP, 1999.

MONTESQUIEU, Charles-Louis de Secondat. Do Espirito das Leis. São Paulo: Brasil Editora S-A, 1960.

OLIVEIRA, Lucia Lippi de. A Questão Nacional na Primeira República. São Paulo: Brasiliense, 1990.

PALACIN, Luis. Os Três Grandes Povoamentos de Goiás. Revista do Instituto Histórico e Geográfico de Goiás. Goiânia: nº 8, 1979, p. 81-95.

PRADO Jr., Caio. Formação do Brasil Contemporâneo. São Paulo: Publifolha, 2000.

PRADO, Paulo. Retrato do Brasil - ensaio sobre a tristeza. São Paulo: Cia das Letras, 1997 [1928].

PRATT, Mary Louise. Os Olhos do Impéric: relatos de viagem e transculturação. Bauru: Edusc, 1999.

REIS, José Carlos. As Identidades do Brasil 2, de Calmon a Bomfim - A favor do Brasil: direita ou esquerda? Rio de Janeiro: FGV, 2006.

REIS, José Carlos. As Identidades do Brasil 3, de Carvalho a Ribeiro: história plural do Brasil. Rio de Janeiro: FGV, 2017.

SANTOS, Myrian Sepúlveda dos. A Escrita do Passado em Museus Históricos. Rio de Janeiro: Garamond; Minc/IPHAN/DEMU, 2006.

SEVCENKO, Nicolau. Introdução. O Prelúdio Republicano, Astúcias da Ordem e Ilusões do Progresso. In: NOVAIS, Fernando (org.). História da vida privada no Brasii. República: da Belle Époque à Era do Rádio. São Paulo: Companhia das Letras, 1999, vol. 3, p. 07-48.

SEVILHA, Fabíula. Rios e Terras: História Ambiental de Goiás (1822-1850). Dissertação em História. Assis: Universidade Estadual Paulista - UNESP, 2013.

SEVILHA, Fabíula. Natureza e Civilização: a resistência indígena e as políticas de aldeamento nas margens dos rios Tocantins e Araguaia (1822-1850). Diálogos (on-line), vol. 21, 2017, p. 64-78.

SILVA, Dinair Andrade. Um Intelectual e a História: Americano do Brasil. BSB, Edição do autor, 1982.

SILVA, Vera Alice Cardoso. Estudo Crítico: Nelson de Sena: Ideias e Ideais de um Republicano Conservador. In: GUSTIN, Fádua Maria de Souza \& LANNA JÚNIOR, Mário Cléber Martins (orgs.). Memória Política de 
Minas Gerais - Nelson Coelho de Sena. Belo Horizonte: Fundação João Pinheiro-Centro de Estudos Históricos e Culturais, 2006, p. 31-57.

SOURNIA, Jean-Charles \& RUFFIE, Jacques. As Epidemias na História do Homem. Lisboa: Edições 70, 1984.

VAINFAS, Ronaldo. Colonização, miscigenação e questão racial: notas sobre equívocos e tabus da historiografia brasileira. Tempo, Niterói, no 8, 1999, p. 01-12.

\footnotetext{
${ }^{1}$ Agradeço ao Prof. José Carlos Reis não apenas por ter me apresentado à obra de Raimundo Moraes na disciplina Tempos e Narrativas do Brasil, lá nos idos de 2013, mas também por ter sido o leitor da primeira versão deste texto, estimulando muitas das reflexões nele contidas - as eventuais falhas e omissões, é claro, são de minha inteira responsabilidade. Agradeço também à Profa. Regina Horta Duarte, orientadora da pesquisa de doutorado cujos resultados foram aqui, em alguma medida, contemplados; e à CAPES (PROEX) pela bolsa usufruída no período.

${ }^{2}$ Sobre Minas Gerais, ver: Lenharo (1979), Libby (1988) e Graça Filho (2002); sobre Goiás, ver Bertran (1988) e Sevilha (2013); sobre a Amazônia, ver Costa (2019).

${ }^{3}$ Uma observação necessária refere-se à Minas Gerais como um estado marcado por diferenças importantes de uma região para outra. Quando Nelson de Senna reivindica um lugar na nação ele pensa mais comumente na região norte do estado, então economicamente estagnada. Mas, quando se dedica ao estudo da história, seu olhar é ampliado para Minas Gerais em sua totalidade.

${ }^{4}$ Estamos cientes de que a Amazônia é um bioma de dimensões continentais, rica em diversidade cultural, social e biológica. A opção por abordá-la na comparação com dois estados deve-se ao caráter da própria obra de Raimundo Moraes, que, ao contrário de Nelson de Senna e Americano do Brasil, tem justamente esse olhar mais geral, que ora se detém ao Vale do Amazonas, ora se refere à Amazônia como um todo.

${ }^{5}$ Como exemplos desses "centros de debate" e elaboração de uma história nacional, além do Instituto Histórico e Geográfico Brasileiro (Gomes, 2009), poderíamos citar o Museu Paulista (Brefe, 2005), o Museu de História Nacional (Santos, 2006) e a Biblioteca Nacional (Caldeira, 2015), bem como a Revista do Brasil (Luca, 1999) e o Almanaque Brasileiro Garnier (Dutra, 2005).

${ }^{6}$ Apenas para ficar nos estudos que difundiram essa visão sobre Goiás, podemos citar os trabalhos de Bruno (1967) e Palacin (1979).

${ }^{7}$ Como nos lembra John Hemming (2011, p. 232), em 1867, durante a febre da borracha e sob pressão da GrãBretanha e dos Estados Unidos, "o Brasil fez do rio Amazonas uma via navegável internacional, aberta a navios mercantes de todas as nações".

${ }^{8}$ Como deputado federal, no contexto das disputas nacionalistas em torno da questão siderúrgica que marcou o governo de Arthur Bernardes na Presidência da República (1922-1926), a postura de Nelson de Senna se mostrou mais ponderada, até mesmo receosa em relação à entrada de capitais estrangeiros.
} 